\section{SOME NEW FORMS OF GEODETICAL} INSTRUMENTS.

THE optical principles involved in gun-sighting apparatus, described in the issue of NATURE for January 9, 1902 (p. 226, vol. lxv.), have been further developed by Sir Howard Grubb, F.R.S., and applied to some new forms of geodetical instruments. In the gunsighting apparatus alluded to, a virtual image of an illuminated cross is optically projected on to the object aimed at, and both the cross and the object are easily seen without any refocussing or straining of the eyes. In the case of the gun sights and also the present instruments, light traverses a plate of glass coated with a very thin film of galena; by this means reflection of light from the surface of the glass is greatly increased, while but little transmitted light is shut off. The process of depositing galena is due in the first instance to Prof. J. Emerson Reynolds, F.R.S. ; it is described in the Proc. Chem. Soc. for I 884 , under the heading "The Synthesis of Galena by means of Thiocarbamide."

The process has been modified by Mr. G. Rudolf Grubb and applied with great success to some new forms of surveying instruments. These instruments have not

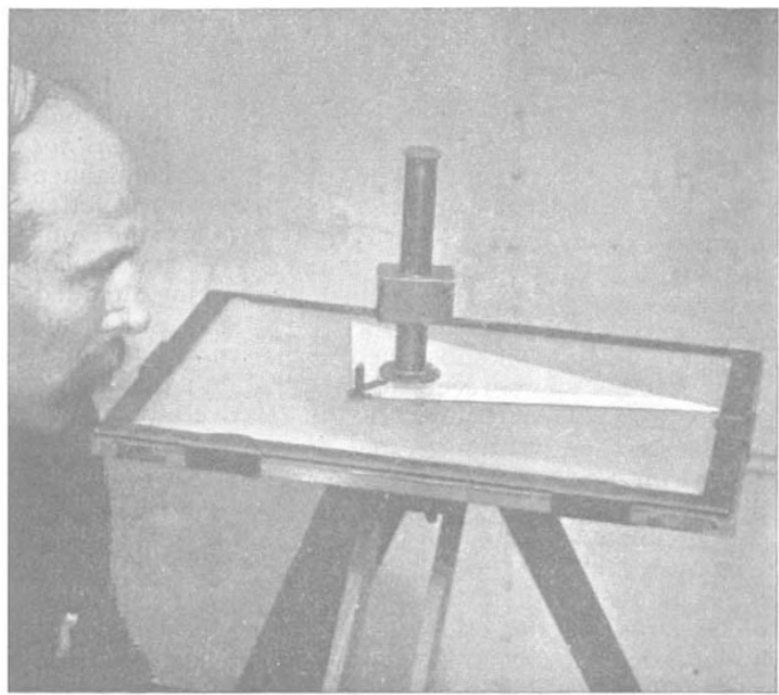

Fic. I.

been designed to take the place of the standard instruments of the engineer, namely the level and the theodolite, but to place in the hands of comparatively inexperienced observers, a ready means of making a rapid survey with an accuracy as great as can be attained in plotting a survey on paper. In the case of ordinary surveying, for example, in road making and in the conveyancing of property, the accuracy of the survey is limited by the degree of precision with which it can be actually plotted on paper with a pencil giving fine lines. When the theodolite is used, the readings are first entered in the field book and then afterwards plotted on paper, the angles being set off with a protractor. By means of the new instrument, the survey is continuously plotted as the instrument is being used. In Fig. I the new form of plane table is shown. The central pillar, through which the successive bearings are taken, is shown in section in Fig. 2 ; it is mounted on a triangular base, or set square, which can be rotated about a point situated in the centre of the paper on the plane table. The instrument is used thus. The sight tube is rotated until its fixed line coincides with a given object, a line is then ruled, it is again moved through some angle till the line coincides with a second fixed object, and another line is ruled along the

NO. I 707, VOL. 66] edge of the set square, the process being repeated until the position of the last fixed object is recorded. Then the whole plane table is moved to a fresh station at a measured distance from the first station, and similar observations are made on the same fixed objects; the intersections of the two sets of bearings give the points

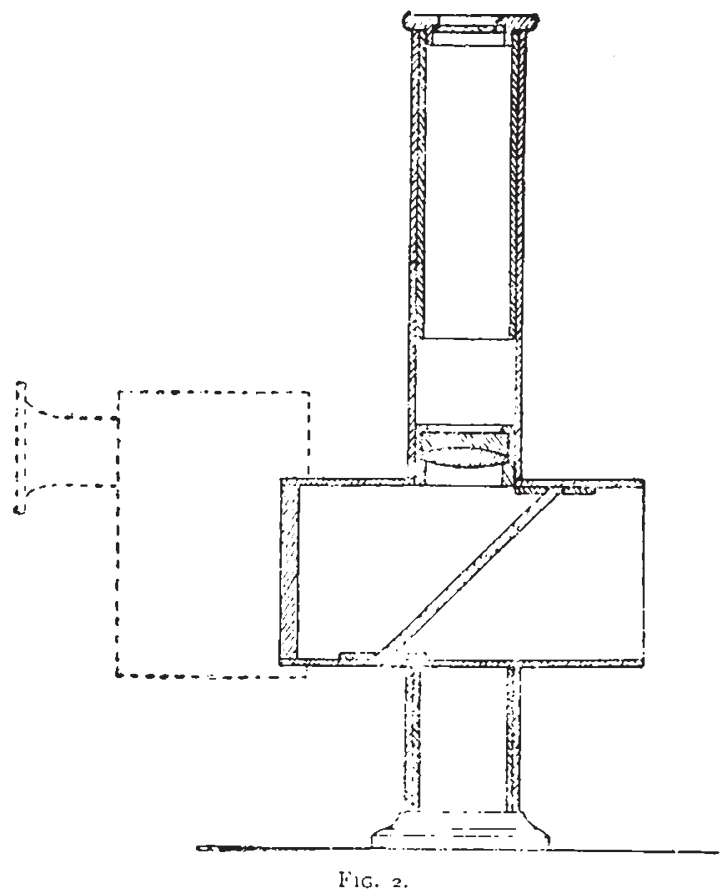

required for the survey. In the case of the survey of a small area, the instrument is not shifted to a new station, but the distances corresponding to the ruled lines are determined by reading the number of divisions which appear in the field of the instrument between two marks

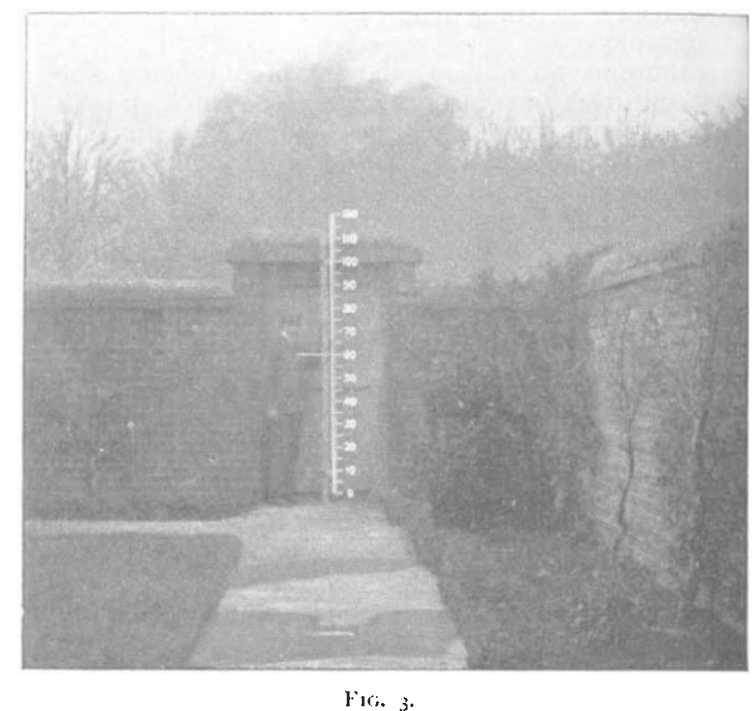

of known distance apart on a staff held at a fixed point. The instrument thus becomes a telemeter, and by means of a suitable scale the distance along any given direction is found and marked on the paper. The actual method of using the instrument is as follows:-The staff man 
walks round a field and successively plants his staff upright where a change in the directions of the boundary occurs; at each point the observer at the plane table rules the direction line and marks the distance, repeating the operation for each successive point, so that the survey of the field is made during the time taken by the staff man in walking round the field and making the necessary halts at each point for the observation to be recorded. The scale and view photographed through the plane table instrument is shown in Fig. 3.

The same optical principle has also been employed by Sir Howard Grubb in the construction of a level to be used in making rapid estimates of gradients in road making and laying out property.

The observer sees at the same instant a fiducial mark, the bubble of the level, and an arc marked with degrees projected on to the field of view.

The excellent optical device has also been utilised in the construction of a prismatic compass and a clinometer.

\section{HERVE FAYE.}

$A$ LL who have taken any interest in the advance of science, more particularly in the direction of astronomy and meteorology, will hear with regret of the death of M. Hervé Faye, which sad event was announced last week. A long course of scientific industry has marked his career, and a great distance seems to separate the workers of to-day from the epoch when Faye and many others, whose names are now but a matter of history, laboured strenuously and successfully to make the paths for their successors more easy and of more rapid attainment. Nearly sixty years have passed since M. Faye first came prominently before the world as the discoverer of a comet, to which his name has always been attached, and it will serve to make us appreciate the advance accomplished in one lifetime if we recall the fact that this was the first elliptic comet the period of which was determined by calculation alone, without any assistance drawn from observations made at previous returns. Faye, at that time an assistant in the Paris Observatory, recognised the necessity of computing an elliptic orbit, but the credit of determining the first orbit of considerable eccentricity from a few days' observations belongs to Goldschmidt, who was stimulated to the task by Gauss. Then the information and the methods of the Theoric Motus had not filtered through a score of text-books and come into the hands of numberless computers, whose deftness of calculation had been whetted by the discovery of hundreds of asteroids, the orbits of which stood in need of determination.

But it will be rather on his philosophical writings than his scientific observations that the reputation of Faye will rest and be honoured by his countrymen. It may be that to some of his theories a general assent has not been given, and that in some cases later discoveries have modified the views the distinguished physicist expressed, but no doubt will be entertained concerning the clearness and ability with which those views have been uttered, or of the influence they have had on French thought. Ever since the time that Laplace in a few pregnant sentences sketched the plan on which the solar system might have been constructed, the subject has been a favourite speculation among French physicists. M. Faye has not been able to resist the temptation to attack this subject, and though, like all attempts at universe construction, the scheme of $M$. Faye fails to meet all the difficulties which beset the problem, yet it is a most suggestive contribution to the subject, and should prove an incentive to further inquiry. In some respects this cosmogonic theory contrasts very favourably with that of Laplace, and in others, as was natural, it falls behind that of his great predecessor ; but this is not the place to enter into any details or criticisms of the argument developed. In recalling, however, the services which M. Faye rendered, one would not willingly forget this finished essay ("Sur l'Origine du Monde"), in which is given, with much that is suggestive, a lucid explanation of the state of our knowledge of the solar and stellar systems.

Similarly, it would be out of place to discuss here the views he expressed on the constitution of the sun, the causes of sun-spots, the behaviour of solar prominences or the chemistry of the sun generally. All these are subjects that fell under Faye's notice and which he treated broadly and philosophically, but necessarily without the facts and knowledge that later observations have brought to light. In cosmical physics and chemistry he was to a great extent a pioneer, and if his theories are in some cases for this reason insufficiently supported by exact observation, they are generally characterised by a breadth of view and thoroughness of conception that contrasts favourably with contemporary opinion. In the discussion of problems connected with cosmical meteoro$\operatorname{logy}$, or with the motions of our own atmosphere, he was, perhaps not so happy, and his writings on cyclonic motions, the laws of storms, the behaviour of tornadoes, and the exceptional phenomena which we occasionally experience will probably be soon forgotten. Not so, however, with such works as the "Cours d'Astronomie nautique" and other mathematical books with which he has enriched French literature, and which are models of arrangement and of clearness of expression.

One could with difficulty recall the numerous services which M. Faye rendered to his (jovernment or the acknowledgments that he received from foreign scientific bodics. He was, of course, Membre de l'Institut and besides a seat at the Bureau des Longitudes which he had occupied since 1862 , in succession to Biot, he was called by Marshal MacMahon to fill in his Cabinet the office of Minister of Instruction, at a time when it was thought not impossible that M. Faye might have become Iirector of the Paris ()bservatory in succession to Le Verrier. He was elected a Foreign Associate of the Royal Astronomical Society so long ago as 1848 , while Belgium, Venice, the United States of America enrolled him among the members of their scientific societies. Full of years and distinction he is removed from us, and with him another link that connects the science of to-day with the science of the past.

\section{W. E. P.}

\section{NOTES.}

THE new botanical laboratories of the Chelsea Physic Garden are to be opened by Earl Cadogan at a garden party there on Firiday, July 25.

A REUTER telegram from Kronstadt in yesterday's Times reports that on July it the Italian cruiser Carlo dllierto received, for the first time, messagcs by wireless telegraphy from the Poldhu station in Cornwall. These are the first experiments in wireless telegraphy over a distance of 1600 English miles in a straight line by land, and the results are said to have been most successful, the messages received having been very distinct.

Amoxg the Civil List Pensions announced in a Parliamentary Paper just issued are the following:-Mr. W. H. Hudson, in recognition of the originality of his writings on natural history, I50l.; the Kev. Dr. John Kerr, F.R.S., in recognition of his valuable discoveries in physical science, I00l.; Mrs. S. C. Jones, in recognition of the services rendered by her late husband, Principal John Viriamu Jones, to the cause of higher education in Wales, $75 \%$; and Mr. H. Ling Koth in consideration of his services to anthropology, $70 l$. 